\title{
Influence of anatomic location of lidocaine patch $5 \%$ on effectiveness and tolerability for postherpetic neuralgia
}

This article was published in the following Dove Press journal:

Patient Preference and Adherence

17 June 2013

Number of times this article has been viewed

\author{
Srinivas Nalamachu' \\ Matthew Wieman ${ }^{2}$ \\ Leah Bednarek ${ }^{2}$ \\ Surya Chitra ${ }^{2}$ \\ 'International Clinical Research \\ Institute, Overland Park, KS, \\ ${ }^{2}$ Endo Pharmaceuticals Inc, \\ Malvern, PA, USA
}

\begin{abstract}
Purpose: Lidocaine patch 5\% is recommended as a first-line therapy for postherpetic neuralgia pain in neuropathic pain guidelines. Postherpetic neuralgia can occur anywhere on the body but often follows acute herpes zoster occurring in trigeminal and brachial plexus dermatomes. An analysis was conducted to determine whether the anatomic location of lidocaine patch $5 \%$ is associated with variations in effectiveness or tolerability in patients with postherpetic neuralgia. Methods: This was a post hoc analysis by anatomic site of patch placement (head [including neck], trunk [chest, abdomen, back, hips], and extremities [arm, leg]) of a 4-week, multicenter, open-label study that enrolled patients with persistent pain following herpes zoster infection. Effectiveness was measured by Brief Pain Inventory (BPI) average pain intensity (0 [no pain] to 10 [worst imaginable pain]) and the BPI subscale for pain relief ( $0 \%$ [no relief] to $100 \%$ [complete relief]). Tolerability was assessed on the basis of patient-reported adverse events.

Results: Of 332 enrolled patients $(59.6 \%$ women $[n=198]$; $92.5 \%$ white $[n=307]$; mean [standard deviation] age, 71.2 [13.9] years), those $(\mathrm{n}=203)$ who applied lidocaine patch $5 \%$ to a single anatomic site only and had baseline and postbaseline pain score data were analyzed (trunk, $\mathrm{n}=130$; head, $\mathrm{n}=41$; extremities, $\mathrm{n}=32$ ). The frequency of adverse events differed significantly by anatomic location, with significantly more adverse events reported with patch placement on the head versus the extremities $(P=0.006)$ or trunk $(P=0.02)$. BPI average pain improved significantly from baseline in each of the three anatomic areas (mean score decrease, 1.50-2.04; $P \leq 0.002$ ), with no significant difference in effectiveness by patch location.

Conclusion: Lidocaine $5 \%$ patch was effective and generally well tolerated for each anatomic area evaluated, although application to the head was tolerated less well compared with the trunk and extremities.
\end{abstract}

Keywords: acute herpes zoster, analgesia, efficacy, lidocaine, postherpetic neuralgia, topical therapies

\section{Introduction}

Acute herpes zoster (AHZ), or "shingles," results from reactivation of latent varicella zoster virus (VZV), the causative agent of chickenpox. ${ }^{1}$ Risk factors associated with reactivation of VZV include advancing age, mental and physical stress, certain disease states (eg, HIV infection), and immunosuppressant treatment regimens (eg, tumor necrosis factor blockade, cyclophosphamide, methotrexate, and others) that compromise cell-mediated immunity responsible for controlling VZV and thus the emergence of AHZ. ${ }^{2-6}$

Although latent VZV is asymptomatic, reactivation of the virus to AHZ is manifested clinically by blistering skin eruptions that are often described as red, maculopapular eruptions evolving into vesicles, pustules, and crusts over a period of 7 to 10 days. ${ }^{7}$
Correspondence: Matthew Wieman Endo Pharmaceuticals Inc, I 400 Atwater Drive, Malvern, PA 19355, USA

$\mathrm{Tel}+\mathrm{I} 4842166489$

$\mathrm{Fax}+\mathrm{I} 6104846052$

Email wieman.matthew@endo.com 
Pain associated with $\mathrm{AHZ}$ infection typically lasts from 2 to 4 weeks after onset of the rash; however, $10 \%-30 \%$ of patients experience postherpetic neuralgia (PHN), a form of pain often lasting $>4$ months after the appearance of the rash. ${ }^{7-9}$

Several agents have demonstrated effectiveness and are recommended on evidence-based guidelines as first-line therapy for PHN, including orally administered tricyclic antidepressants (eg, amitriptyline and others), antiepileptics (ie, gabapentin, pregabalin), and topical lidocaine patch $5 \% .^{7,10-12}$ Lidocaine patch $5 \%$ is approved for the relief of pain associated with PHN when applied to intact skin. ${ }^{13}$ Importantly, the results of a meta-analysis showed effective pain relief achieved with administration of lidocaine patch $5 \%$ in patients with PHN was associated with significantly fewer adverse events (AEs) and discontinuations, compared with orally administered agents (ie, gabapentin, pregabalin). ${ }^{14}$

Although PHN can appear anywhere on the body, asymptomatic VZV typically persists in sensory cranial nerves and spinal dorsal root ganglia; ${ }^{15}$ thus, locations affected with $\mathrm{PHN}$ often include the head (eg, trigeminal plexus), trunk, and extremities (eg, brachial plexus). ${ }^{2,16}$ The objective of this post hoc analysis was to determine whether the anatomic location of the application of lidocaine patch $5 \%$ is associated with variation in measures of effectiveness and tolerability for relief of PHN pain.

\section{Methods}

\section{Study design and participants}

This post hoc analysis examined the safety and efficacy of the lidocaine patch 5\% (Lidoderm ${ }^{\circledR}$, Endo Pharmaceuticals Inc, Malvern, PA, USA) by anatomic location (ie, head, trunk, extremities) of the patch in patients with PHN enrolled in a 4-week, multicenter, open-label study. Patients in the original study had chronic local pain following AHZ (median duration of pain after AHZ, 11.3 months; range, 1 month to 23 years). The methodologic details of the original study have been published previously. ${ }^{17}$

This post hoc analysis included patients who had applied lidocaine patch $5 \%$ to only one anatomic location. Patients who had applied study medication to more than one anatomic location were excluded from the analysis because multiple locations was considered to be a confounding variable. The study was conducted according to the Declaration of Helsinki, International Conference on Harmonisation for Good Clinical Practice, applicable regulatory requirement, and Institutional Review Board review. All study participants provided written informed consent before the initiation of any study procedures.

\section{Treatments}

Patients were instructed to apply lidocaine patches 5\% daily (equal to or less than four patches per day), to the area of maximal peripheral pain, for no more than 12 hours within any given 24-hour period. Patients were also instructed to cover as much of the affected area as possible and to apply the patches at the same time each day. Patients were permitted to continue previous medications.

\section{Assessments}

Effectiveness of the lidocaine patch 5\% was measured using the Brief Pain Inventory (BPI) Short Form subscales of pain intensity (11-point Likert scale: $0=$ no pain, $10=$ worst imaginable pain) over the previous 24 hours. ${ }^{17,18}$ BPI pain intensity was assessed by anatomic location (ie, head, including the neck; trunk, including the chest, abdomen, back, and hips; and extremities, including the arms and legs); and scale scores (ie, worst pain, average pain, least pain, pain right now) after treatment were compared with scores at baseline. Effectiveness was also measured with the BPI subscale for pain relief $(0 \%=$ no relief, $100 \%=$ complete relief $)$ that describes the response to treatment, with the baseline value representing relief obtained with other therapies before treatment with lidocaine patch 5\%. Tolerability was assessed in all treated patients based on patient-reported AEs. Patients were instructed to maintain a diary of responses to the lidocaine patch 5\% and record any AEs experienced during the 28-day treatment period. Patients were interviewed by telephone on treatment days 7 and 14 and were assessed in person by the investigator on final treatment day 28.

\section{Statistical analyses}

Demographic data and baseline clinical characteristics by anatomic site treated were summarized using descriptive statistics. Effectiveness measures were summarized and assessed from day 0 to days 7 and 28 with an alpha level of 0.05 using version 6.12 of SAS (SAS Institute, Cary, NC, USA; primary Proc Univariate, Freq, and Mixed). ${ }^{19}$ Common AEs in the entire study population were summarized using descriptive statistics. Treatment-emergent AEs summarized by anatomic location of the lidocaine patch $5 \%$ were compared using Fisher's exact test.

\section{Results}

\section{Patients}

Overall, patients enrolled in the trial were predominantly of advanced age (mean age, 71.2 years), female (59.6\%), and white $(92.5 \%)$. Demographic characteristics were generally 
similar across treatment sites (Table 1). Of the 332 patients enrolled, 203 patients had applied the lidocaine patch 5\% to only one anatomic location and were included in this post hoc analysis. The remaining patients $(n=129)$ had applied the lidocaine patch $5 \%$ to more than one anatomic location and were excluded from this analysis.

The BPI average pain intensity subscale score at baseline was between 5.4 and 6.0, depending on the anatomic location (Table 1). Baseline pain relief represents the effect of previous treatment regimens used before initiation of treatment with the lidocaine patch $5 \%$. Baseline pain ratings were generally similar regardless of treatment location (Table 1).

\section{Efficacy}

After treatment with lidocaine patch 5\%, BPI pain intensity subscales improved significantly from baseline in the head, trunk, and extremities, similar to the overall BPI pain intensity subscales scores from the original study (Table 2). However, the effectiveness of lidocaine patch $5 \%$ did not differ by anatomic location of the patch (ie, head versus trunk, head versus extremities, trunk versus extremities) (Table 3; Figures 1 and 2).

\section{Safety}

The most commonly reported AEs in the entire study population were localized skin and subcutaneous tissue reactions and rash (Table 4), of which 89\% (40/45) were treatment related. Most (29 [72.5\%]) treatment-related skin reactions

Table I Baseline demographics and clinical characteristics

\begin{tabular}{|c|c|c|c|}
\hline $\begin{array}{l}\text { Patient } \\
\text { characteristics }\end{array}$ & $\begin{array}{l}\text { Head } \\
(n=4 I)\end{array}$ & $\begin{array}{l}\text { Trunk } \\
(n=130)\end{array}$ & $\begin{array}{l}\text { Extremities } \\
(n=32)\end{array}$ \\
\hline \multicolumn{4}{|l|}{ Sex, n (\%) } \\
\hline Women & $26(7.8)$ & II 8 (35.4) & $18(5.4)$ \\
\hline Men & $28(8.4)$ & $61(18.3)$ & $14(4.2)$ \\
\hline \multicolumn{4}{|l|}{ Race, n (\%) } \\
\hline Black & 0 & $8(2.4)$ & 0 \\
\hline Asian & 0 & $2(0.6)$ & 0 \\
\hline White & $53(15.9)$ & 161 (48.3) & $31(9.3)$ \\
\hline Hispanic & 0 & $4(1.2)$ & I (0.3) \\
\hline Other & 0 & $\mathrm{I}(0.3)$ & 0 \\
\hline \multicolumn{4}{|l|}{ Age, years } \\
\hline Mean (SD) & $73.4(12.1)$ & $70.6(14.0)$ & $76.0(14.3)$ \\
\hline Range & $25-94$ & $20-92$ & 27-99 \\
\hline \multicolumn{4}{|c|}{ Mean (SD) BPI pain scores } \\
\hline Worst pain & $7.0(2.1)$ & $7.4(2.0)$ & $7.0(2.1)$ \\
\hline Least pain & $3.5(2.0)$ & $3.6(2.2)$ & $3.7(2.2)$ \\
\hline Average pain & $5.4(1.4)$ & $6.0(1.6)$ & $5.8(1.7)$ \\
\hline Pain right now & $4.7(2.7)$ & $5.5(2.5)$ & $5.2(2.9)$ \\
\hline Pain relief, \% & $34.8(27.8)$ & $36.6(28.1)$ & $19.5(23.1)$ \\
\hline
\end{tabular}

Abbreviations: BPI, Brief Pain Inventory; SD, standard deviation. were mild, $6(15 \%)$ were moderate, and $5(12.5 \%)$ were severe. No serious treatment-related AEs were observed.

The frequency of AEs differed by anatomic location (Table 5), with significantly more AEs reported with patch placement on the head versus the extremities $(P=0.02)$ or trunk $(P=0.006)$; there was no significant difference in frequency of AEs with patch placement on the trunk versus the extremities.

\section{Discussion}

This post hoc analysis demonstrates that lidocaine patch $5 \%$ is effective and generally well tolerated when topically administered at different anatomic locations, primarily in patients of advanced age with PHN, who presented with clinical evidence of AHZ. Skin reaction, the most commonly observed treatment-related AE, was mild in most cases $(72.5 \%)$. However, tolerability with patch placement on the trunk or extremities was significantly better compared with patch placement on the head and neck. Patients exhibited significant improvement from baseline in pain intensity when lidocaine patch 5\% was applied to the head, trunk, and extremities, with no significant differences in efficacy by anatomic location of the patch (Figures 1 and 2).

The results of this post hoc analysis are clinically relevant, because first-line therapies for relief of PHN pain, including lidocaine patch 5\%, tricyclic antidepressants, gabapentin and pregabalin, have been assessed in neuropathic pain guidelines and systematic reviews as having similar efficacy, but the lidocaine patch $5 \%$ has been described as comparatively safe and well tolerated because of its localized action with limited systemic absorption. ${ }^{12,20,21}$ Consequently, it is important to determine whether factors such as anatomic location of the lidocaine patch $5 \%$ have an impact on its tolerability.

In one study, fewer patients administered lidocaine patch $5 \%$ experienced any AEs (18.7\% versus 46.4\%), treatmentrelated AEs (TRAEs) (5.8\% versus $41.2 \%)$, and discontinuations due to TRAEs $(2.6 \%$ versus $23.5 \%)$, compared with pregabalin. ${ }^{22}$ TRAEs occurring in more than one patient included application site irritation and headache with lidocaine patch $5 \%$ (1.3\% for each), dizziness (11.8\%), fatigue $(8.5 \%)$, vertigo $(7.8 \%)$, somnolence $(5.2 \%)$, and headache $(4.6 \%)$. The majority of TRAEs reported in patients who applied lidocaine patch 5\% were mild (56.3\%); 37.5\% were moderate and $6.2 \%$ were severe. TRAEs with pregabalin were less likely to be mild $(37.3 \%)$ and more likely to be moderate $(45.3 \%)$ or severe $(17.4 \%)$. In the same study, 
Table 2 Change in mean pain score (baseline to final)

\begin{tabular}{|c|c|c|c|c|c|c|c|c|c|c|c|c|}
\hline \multirow[b]{2}{*}{ BPI subscale ${ }^{d}$} & \multicolumn{3}{|l|}{ Head $^{a}$} & \multicolumn{3}{|l|}{ Trunk $^{\mathrm{b}}$} & \multicolumn{3}{|c|}{ Extremities $^{c}$} & \multicolumn{3}{|l|}{ Overall } \\
\hline & $\begin{array}{l}\text { Mean } \\
\text { change }\end{array}$ & SD & $P$ value & $\begin{array}{l}\text { Mean } \\
\text { change }\end{array}$ & SD & $P$ value & $\begin{array}{l}\text { Mean } \\
\text { change }\end{array}$ & SD & $P$ value & $\begin{array}{l}\text { Mean } \\
\text { change }\end{array}$ & SD & $P$ value \\
\hline Worst pain & -2.15 & 2.89 & $<0.001$ & -2.07 & 2.5 & $<0.001$ & -1.68 & 2.98 & 0.003 & -2 & 2.7 & $<0.001$ \\
\hline Least pain & -1.63 & 2.13 & $<0.001$ & -1.29 & 2.72 & $<0.001$ & -0.687 & 3.31 & 0.2 & -1.2 & 2.6 & $<0.001$ \\
\hline Average pain & -1.83 & 2.2 & $<0.001$ & -2.04 & 2.24 & $<0.001$ & -1.5 & 2.42 & 0.001 & -1.9 & 2.3 & $<0.001$ \\
\hline Pain right now & -1.96 & 2.63 & $<0.001$ & -2.44 & 3.21 & $<0.00$ I & -2.03 & 3.47 & 0.003 & -2.1 & 3 & $<0.001$ \\
\hline Pain relief ${ }^{e}$ & 18.29 & 38.84 & 0.008 & 21 & 39.55 & $<0.001$ & 29.83 & 29.13 & $<0.001$ & 23.2 & 35.2 & $<0.001$ \\
\hline
\end{tabular}

Notes: ${ }^{a} \mathrm{Head}$ and neck; ${ }^{\mathrm{C}}$ Chest, abdomen, and hips; 'Arms and legs; ${ }^{\mathrm{d} P a i n}$ intensity, difference in change from baseline $\left(0=\right.$ no pain, $10=$ worst imaginable pain); ${ }^{\mathrm{P}} \mathrm{Pain}$ relief, difference in change from baseline; negative is improvement $(0 \%=$ no relief, $100 \%=$ complete relief).

Abbreviations: BPI, Brief Pain Inventory; SD, standard deviation.

a greater percentage of patients treated with lidocaine patch 5\% than with pregabalin (approximately 63\% versus $47 \%$ ) showed a reduction from baseline in average pain as measured by the Numeric Rating Scale-3, an 11-point scale that uses the same score range as the BPI $(0=$ no pain; 10 = worst imaginable pain) but over 3 days instead of 1 day. ${ }^{22}$ Similarly, the results of a network meta-analysis demonstrated a greater improvement (ie, change from baseline) in pain relief for lidocaine patch $5 \%$ (mean difference, $-15.50 ; 95 \% \mathrm{CI},-18.85$ to $-12.16 ; P<0.001)$ than for pregabalin $(-2.06 ; 95 \% \mathrm{CI},-7.45$ to $3.34 ; P=0.455)$ and gabapentin $(-7.56 ; 95 \% \mathrm{CI},-12.52$ to $-2.59 ; P=0.003)$ compared with the placebo. ${ }^{14}$ Importantly, the current study demonstrates that lidocaine patch $5 \%$ provides good tolerability with significant improvement in pain intensity and pain relief when applied to different anatomic locations in patients with PHN previously treated with therapeutic regimens other than lidocaine patch $5 \%$ that provided some degree of pain relief at baseline.

Because the sample size of our study is small, extrapolation of the effectiveness and tolerability results to the general clinical patient population should be considered with caution. However, the study population demographics seem to reflect the epidemiologic profile of the general population.
An analysis of large population databases showed that the overall incidence of AHZ increased from 1.7 per 1000 individuals in 1998 to 4.4 per 1000 in 2006 and was highest among those $\geq 65$ years of age. ${ }^{23}$ A survey of individuals $\geq 65$ years of age revealed that the self-reported incidence of AHZ disease (ie, shingles) was significantly higher among white $(2.1 \%$ versus $0.6 \% ; P=0.009$ ) compared with Hispanic individuals, but did not differ between black and white or Hispanic and black respondents. ${ }^{24}$ An analysis of a large sentinel practice network showed an overall 28\% age-adjusted excess incidence of AHZ in women (ie, mean incidence, 470 versus 367 per 100,000) compared with men. ${ }^{25}$ The post hoc analysis presented here included patients $\geq 65$ years of age who were predominantly women, and white, and presented with clinical evidence of AHZ and PHN. Nonetheless, the sample size of the current analysis may be too small to allow for firm conclusions about efficacy and tolerability in the general population.

A limitation of this study was the exclusion of patients with multiple locations of application of lidocaine patch 5\%; this was done because interpretation of pain scores in patients with multiple sites was considered a potential confounder. Even so, the finding that lidocaine patch $5 \%$ is well tolerated in this cohort of predominantly patients of advanced age

Table 3 Comparison of differences in effectiveness by anatomic location of patch

\begin{tabular}{|c|c|c|c|c|c|c|}
\hline \multirow[b]{2}{*}{ BPI Subscale ${ }^{d}$} & \multicolumn{2}{|l|}{ Head $^{\mathrm{a}}$ versus trunk ${ }^{\mathrm{b}}$} & \multicolumn{2}{|l|}{ Head $^{a}$ versus extremities $^{c}$} & \multicolumn{2}{|l|}{ Trunk $^{b}$ versus extremities $^{c}$} \\
\hline & Difference in effectiveness & $P$ value & Difference in effectiveness & $P$ value & Difference in effectiveness & $P$ value \\
\hline Worst pain & 0.08 & 0.1 & 0.47 & 0.5 & 0.39 & 0.5 \\
\hline Least pain & 0.34 & 0.6 & 0.94 & 0.8 & 0.60 & 0.7 \\
\hline Average pain & -0.21 & 0.6 & 0.33 & 0.5 & 0.54 & 0.7 \\
\hline Pain right now & -0.48 & 0.3 & -0.07 & 0.9 & 0.41 & 0.4 \\
\hline Pain relief, ${ }^{e} \%$ & 2.71 & 0.3 & 11.54 & 0.8 & 8.83 & 0.8 \\
\hline
\end{tabular}

Notes: ${ }^{a} \mathrm{Head}$ and neck; ${ }^{\mathrm{b}}$ Chest, abdomen, and hips; 'Arms and legs; ${ }^{\mathrm{C}}$ Pain intensity, difference in change from baseline $\left(0=\right.$ no pain, $10=$ worst imaginable pain); ${ }^{\mathrm{P}} \mathrm{Pain}$ relief, difference in change from baseline $(0 \%=$ no relief, $100 \%=$ complete relief $)$, negative is improvement.

Abbreviation: BPI, Brief Pain Inventory. 


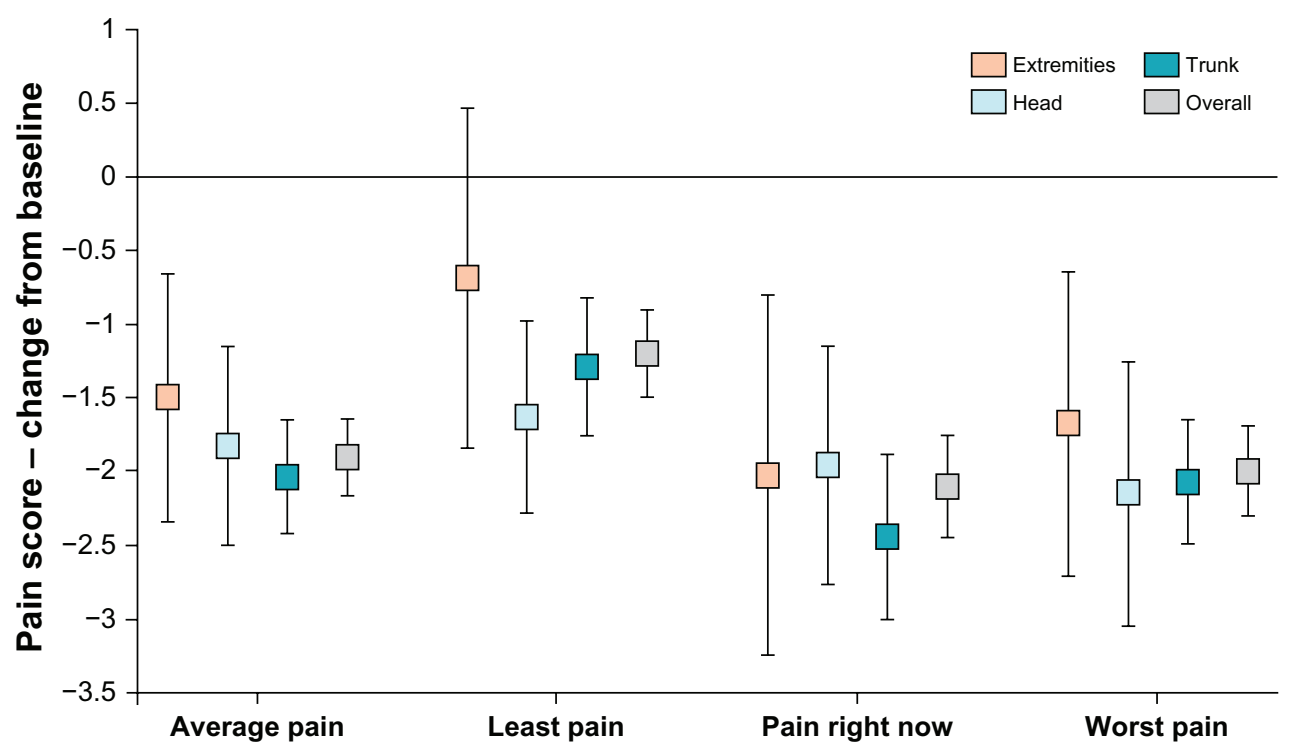

Figure I Brief Pain Inventory change from baseline in pain intensity by anatomic location.

Notes: Pain intensity: $0=$ no pain, $10=$ worst imaginable pain. Extremities = applied lidocaine patch $5 \%$ only to upper or lower limbs; Head = applied lidocaine patch $5 \%$ only to head or neck; Trunk = applied lidocaine patch $5 \%$ only to trunk; Overall = entire study population.

who applied study medication to a single anatomic location (ie, head, trunk, or extremities) is highly relevant in light of the $\mathrm{AE}$ profile of other agents recommended as first-line therapy for PHN. Recognized AEs associated with orally administered agents, such as tricyclic antidepressants (eg, drowsiness, constipation, dry mouth [30\% intolerable], and others) and antiepileptics (eg, drowsiness, ataxia, headache, infection, and others) may limit the use of these agents in some patients. ${ }^{26,27}$

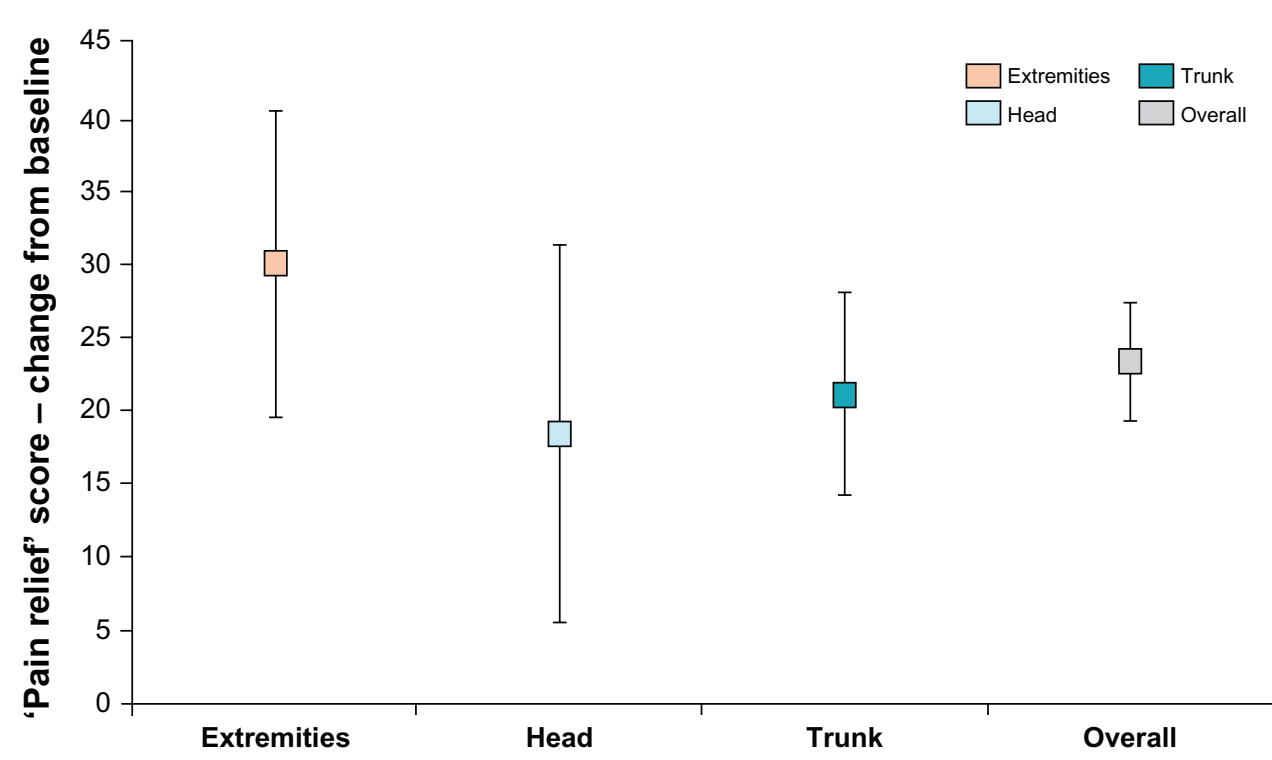

Lidocaine patch 5\%, unlike orally administered agents, was formulated to provide localized rather than systemic drug exposure that reduces the risk for systemic AEs. ${ }^{13}$ This factor may be especially important in patients of advanced age who often present with comorbid conditions, requiring concomitant medications that may increase the risk for unwanted drug-drug interactions. Moreover, studies have repeatedly demonstrated that application of the patch is associated with TRAEs, most commonly application site

Figure 2 Brief Pain Inventory change from baseline in pain relief by anatomic location.

Notes: Pain relief: $0=$ no relief, $10=$ complete relief. Extremities = applied lidocaine patch $5 \%$ only to upper or lower limbs; Head = applied lidocaine patch $5 \%$ only to head or neck; Trunk = applied lidocaine patch $5 \%$ only to trunk; Overall = entire study population. 
Table 4 Summary of clinical adverse events during treatment with lidocaine patch $5 \%{ }^{17}$

\begin{tabular}{|c|c|c|}
\hline Body system event & $\begin{array}{l}\text { TRAEs, } n \\
\text { (\% of patients) }\end{array}$ & $\begin{array}{l}\text { TEAEs, } n \\
\text { (\% of patients) }\end{array}$ \\
\hline Skin and subcutaneous tissue/rash & $40(12)$ & $45(14)$ \\
\hline Nervous system & $19(6)$ & $31(9)$ \\
\hline General disorders & $16(5)$ & $26(8)$ \\
\hline Cardiac & $2(<1)$ & $8(2)$ \\
\hline $\begin{array}{l}\text { Musculosketetal, connective } \\
\text { tissue, and bone disorders }\end{array}$ & $\mathrm{I}(<\mathrm{I})$ & $7(2)$ \\
\hline Infections & 0 & $7(2)$ \\
\hline Eye & $3(1)$ & $4(1)$ \\
\hline Psychiatric & $2(<1)$ & $4(1)$ \\
\hline $\begin{array}{l}\text { Respiratory, thoracic, } \\
\text { and mediastinal }\end{array}$ & 0 & $4(1)$ \\
\hline Immune system & $3(<1)$ & $3(<1)$ \\
\hline Vascular & $\mathrm{I}(<\mathrm{I})$ & $2(<1)$ \\
\hline Ear/labyrinth & $\mathrm{I}(<\mathrm{I})$ & $2(<1)$ \\
\hline Renal and urinary & 0 & $2(<1)$ \\
\hline Injury and poisoning & $\mathrm{I}(<\mathrm{I})$ & $\mathrm{I}(<\mathrm{I})$ \\
\hline Neoplasms, benign, and malignant & 0 & $\mathrm{I}(<\mathrm{I})$ \\
\hline Surgical and medical & 0 & $\mathrm{I}(<\mathrm{I})$ \\
\hline
\end{tabular}

Abbreviations: TEAE, treatment-emergent adverse event; TRAE, treatmentrelated adverse event.

reactions (eg, localized rash), in a small percentage of patients (eg, $1.4 \%-12 \%$ of patients). ${ }^{17,22,28,29}$ Consistent with these reports, the current study demonstrates that application of lidocaine patch $5 \%$ on the head, trunk, and extremities in predominantly patients of advanced age is generally well tolerated with a low incidence of TRAEs, which were generally mild in severity, and most commonly presented as localized rash. Fewer AEs were reported with patch placement on the extremities and trunk compared with the head, possibly because of differences in skin thickness, sensitivity, and sweating in these areas.

Table 5 TEAEs by anatomic location

\begin{tabular}{|c|c|c|c|}
\hline $\begin{array}{l}\text { Anatomic } \\
\text { location }\end{array}$ & $\begin{array}{l}\text { Patients with } \\
\text { TEAEs, n (\%) }\end{array}$ & $\begin{array}{l}\text { Patients without } \\
\text { TEAEs, } \mathbf{n}(\%)\end{array}$ & $\begin{array}{l}\text { Total } \\
\text { patients, } n\end{array}$ \\
\hline Head $^{a}$ & $17(4 \mid .5)$ & $24(58.5)$ & 41 \\
\hline Trunk $^{\mathrm{b}}$ & $25(19.2)$ & $105(80.8)$ & 130 \\
\hline Extremities $^{c}$ & $5(15.6)$ & $27(84.4)$ & 32 \\
\hline Comparison & $P$ value ${ }^{d}$ & & \\
\hline $\begin{array}{l}\text { Head }^{\mathrm{a}} \text { versus } \\
\text { trunk }^{\mathrm{b}}\end{array}$ & 0.006 & & \\
\hline $\begin{array}{l}\text { Head }^{\mathrm{a}} \text { versus } \\
\text { extremities }^{\mathrm{c}}\end{array}$ & 0.02 & & \\
\hline $\begin{array}{l}\text { Trunk }^{\mathrm{b}} \text { versus } \\
\text { extremities }^{\mathrm{c}}\end{array}$ & 0.80 & & \\
\hline
\end{tabular}

Notes: ${ }^{a} \mathrm{Head}$ and neck; ${ }^{\mathrm{b}}$ Chest, abdomen, and hips; 'Arms and legs; ${ }^{\mathrm{d} P}$ values were calculated using Fisher's exact test.

Abbreviation: TEAE, treatment-emergent adverse event.

\section{Conclusion}

Lidocaine patch 5\% was effective and generally well tolerated when applied to the head, trunk, and extremities in patients with PHN; however, tolerability with patch placement on the trunk and extremities was significantly better compared with patch placement on the head and neck. Our data suggest that the anatomic location of the PHN rash should also be considered when selecting a therapy for reasons of patient preference and compliance, rather than efficacy. Tolerability findings by anatomic site may be confirmed in prospective studies enrolling a larger number of patients with $\mathrm{PHN}$ at different anatomic sites and at multiple sites.

\section{Acknowledgments}

Editorial support for this manuscript was provided by Craig D Albright, PhD and Robert Gatley, MD of Complete Healthcare Communications Inc (Chadds Ford, PA), with funding from Endo Pharmaceuticals Inc (Malvern, PA).

\section{Disclosure}

Dr Nalamachu has served on advisory boards and as a consultant and clinical trial investigator for Endo Pharmaceuticals Inc. He also is a consultant, serves on the advisory board and speakers' bureau, and receives honoraria from ProStrakan, Cephalon, and Covidien. He has authored original research and review articles with support from Endo Pharmaceuticals, but without any associated honoraria, and has presented posters at scientific meetings with reimbursement of associated expenses. All other authors are employees of Endo Pharmaceuticals Inc.

\section{References}

1. Weller TH. Varicella and herpes zoster. Changing concepts of the natural history, control, and importance of a not-so-benign virus. N Engl J Med. 1983;309(22):1362-1368.

2. Weaver BA. The burden of herpes zoster and postherpetic neuralgia in the United States. J Am Osteopath Assoc. 2007;107(3 Suppl 1):S2-S7.

3. Kim SY, Solomon DH. Tumor necrosis factor blockade and the risk of viral infection. Nat Rev Rheumatol. 2010;6(3):165-174.

4. Birlea M, Arendt G, Orhan E, et al. Subclinical reactivation of varicella zoster virus in all stages of HIV infection. J Neurol Sci. 2011;304(1-2): $22-24$.

5. Lin KC, Wang CC, Wang KY, Liao YC, Kuo JR. Reactivation of herpes zoster along the trigeminal nerve with intractable pain after facial trauma: a case report and literature review. BMJ Case Rep. Epub April 28, 2009.

6. Irwin $\mathrm{M}$, Costlow $\mathrm{C}$, Williams $\mathrm{H}$, et al. Cellular immunity to varicella-zoster virus in patients with major depression. $J$ Infect Dis. 1998;178(Suppl 1):S104-S108.

7. Argoff CE. Review of current guidelines on the care of postherpetic neuralgia. Postgrad Med. 2011;123(5):134-142.

8. Fashner J, Bell AL. Herpes zoster and postherpetic neuralgia: prevention and management. Am Fam Physician. 2011;83(12):1432-1437. 
9. Klompas M, Kulldorff M, Vilk Y, Bialek SR, Harpaz R. Herpes zoster and postherpetic neuralgia surveillance using structured electronic data. Mayo Clin Proc. 2011;86(12):1146-1153.

10. Attal N, Cruccu G, Haanpää M, et al; European Federation of Neurological Societies Task Force. EFNS guidelines on pharmacological treatment of neuropathic pain. Eur J Neurol. 2006;13(11): 1153-1169.

11. Dubinsky RM, Kabbani H, El-Chami Z, Boutwell C, Ali H; Quality Standards Subcommittee of the American Academy of Neurology. Practice parameter: treatment of postherpetic neuralgia: an evidencebased report of the Quality Standards Subcommittee of the American Academy of Neurology. Neurology. 2004;63(6):959-965.

12. Dworkin RH, O'Connor AB, Backonja M, et al. Pharmacologic management of neuropathic pain: evidence-based recommendations. Pain. 2007;132(3):237-251.

13. Lidoderm ${ }^{\circledR}$ (lidocaine patch $5 \%$ ) [prescribing information]. Chadds Ford, PA: Endo Pharmaceuticals Inc; 2010.

14. Wolff RF, Bala MM, Westwood M, Kessels AG, Kleijnen J. 5\% lidocaine-medicated plaster vs other relevant interventions and placebo for post-herpetic neuralgia (PHN): a systematic review. Acta Neurol Scand. 2011;123(5):295-309.

15. Nalamachu S, Morley-Forster P. Diagnosing and managing postherpetic neuralgia. Drugs Aging. 2012;29(11):863-869.

16. Berry JD, Rowbotham MC, Petersen KL. Complex regional pain syndrome-like symptoms during herpes zoster. Pain. 2004;110(1-2): e1-e12.

17. Katz NP, Gammaitoni AR, Davis MW, Dworkin RH; Lidoderm Patch Study Group. Lidocaine patch 5\% reduces pain intensity and interference with quality of life in patients with postherpetic neuralgia: an effectiveness trial. Pain Med. 2002;3(4):324-332.

18. Cleeland CS, Ryan KM. Pain assessment: global use of the Brief Pain Inventory. Ann Acad Med Singapore. 1994;23(2):129-138.

19. SAS Institute Inc. The MIXED Procedure. SAS/STAT 9.2 User's Guide. Cary, NC: SAS Institute Inc; 2008.
20. Attal N, Cruccu G, Baron R, et al; European Federation of Neurological Societies. EFNS guidelines on the pharmacological treatment of neuropathic pain: 2010 revision. Eur J Neurol. 2010;17(9):1113-e88.

21. Selph S, Carson S, Fu R, Thakurta S, Low A, McDonagh M. Drug class review: neuropathic pain: final update 1 report. Portland, OR: Oregon Health and Science University; 2011.

22. Baron R, Mayoral V, Leijon G, Binder A, Steigerwald I, Serpell M. 5\% lidocaine medicated plaster versus pregabalin in post-herpetic neuralgia and diabetic polyneuropathy: an open-label, non-inferiority two-stage RCT study. Curr Med Res Opin. 2009;25(7):1663-1676.

23. Leung J, Harpaz R, Molinari NA, Jumaan A, Zhou F. Herpes zoster incidence among insured persons in the United States, 1993-2006: evaluation of impact of varicella vaccination. Clin Infect Dis. 2011;52(3):332-340.

24. Chaves SS, Santibanez TA, Gargiullo P, Guris D. Chickenpox exposure and herpes zoster disease incidence in older adults in the U S. Public Health Rep. 2007;122(2):155-159.

25. Fleming DM, Cross KW, Cobb WA, Chapman RS. Gender difference in the incidence of shingles. Epidemiol Infect. 2004;132(1):1-5.

26. Johnson RW, McElhaney J. Postherpetic neuralgia in the elderly. Int J Clin Pract. 2009;63(9):1386-1391.

27. Douglas MW, Johnson RW, Cunningham AL. Tolerability of treatments for postherpetic neuralgia. Drug Saf. 2004;27(15):1217-1233.

28. Clère F, Delorme-Morin C, George B, et al. 5\% lidocaine medicated plaster in elderly patients with postherpetic neuralgia: results of a compassionate use programme in France. Drugs Aging. 2011;28(9): 693-702.

29. Binder A, Bruxelle J, Rogers P, Hans G, Bösl I, Baron R. Topical 5\% lidocaine (lignocaine) medicated plaster treatment for post-herpetic neuralgia: results of a double-blind, placebo-controlled, multinational efficacy and safety trial. Clin Drug Investig. 2009;29(6):393-408.
Patient Preference and Adherence

\section{Publish your work in this journal}

Patient Preference and Adherence is an international, peer-reviewed, open access journal focusing on the growing importance of patient preference and adherence throughout the therapeutic continuum. Patient satisfaction, acceptability, quality of life, compliance, persistence and their role in developing new therapeutic modalities and compounds to

\section{Dovepress}

optimize clinical outcomes for existing disease states are major areas of interest. This journal has been accepted for indexing on PubMed Central. The manuscript management system is completely online and includes a very quick and fair peer-review system. Visit http://www.dovepress.com/ testimonials.php to read real quotes from published authors. 